\title{
Multiple Sclerosis and the Pathogenicity of Mir-155
}

\author{
Eiman MA Mohammed* \\ Immunology Laboratory, Kuwait Cancer Control Centre, Kuwait
}

Received: 㘹: September 24, 2018; Published: 㠿: October 09, 2018

*Corresponding author: Eiman MA Mohammed Immunology Laboratory, Kuwait Cancer Control Centre, Ministry of Health, Shuwaikh, Kuwait

\section{Mini Review}

Multiple sclerosis (MS) is one of the complex diseases. Genetics, environmental and emotional factors have shown to play essential roles in evoking the disease pathology. More interestingly, epigenetic factors were established as major influencers of the disease severity [1] Of those epigenetic factors; the microRNA (miRNA) plays a fundamental function in MS pathogenicity. MiRNA are small noncoding RNA molecules with a size of approximately 22 nucleotides involved in post-transcriptional regulations of the genes [2-5]. In one of the first published papers on the relation between MS and miRNA, Otaegui and his group found differential miRNA profile between MS patient and healthy volunteers when analyzing 364 peripheral blood mononuclear cells (PBMC) samples. More so, they found that even between MS patients, miRNA profile can differentiate between remissions and relapses stages [6]. One of the most attractive miRNA associated with MS was the miR-155. In 2009, Junker et al have for the first time identified miR-155 upregulation in active MS lesions [7]. Subsequently, many have established the role of this miRNA in relapsing stages of MS and experimental autoimmune encephalomyelitis (EAE) [4,8-15].

MiR-155 was of interest due to its important roles in immune system regulation. This miRNA has been proven to target the suppressor of cytokine signaling -1 (SOSC1); a negative regulator of cytokines signaling. It was also proven to induce T-cell differentiation along the T-helper 17 (Th17) and T-helper 1 (Th1) cells lines [1619]. MiR-155 was, moreover, documented to target transcription factor Ets1; a negative modulator of Th17 differentiation [20]. Additionally, it targets CD47; a molecule involved in self-recognition and protect cells from phagocytosis [21]. It, more so, suppresses src homology 2 domain-containing inositol-5-phosphatase 1 (SHIP1); a known negative inhibitor of pro-inflammatory pathways to macrophages (MØ) and dendritic cells (DCs) [20]. Besides all that, miR-155 can suppress essential neuro-steroids in the white matter of MS cases [21,22]. And was noted to increase the tumor necrosis factor - $\alpha(\mathrm{TNF} \alpha)$ and monocyte chemoattractant protein-1 (MCP1) expression in a toll-like receptor -4 (TLR4)-dependent manner, resulting in neuro-inflammation in the cerebellum [23].
Captivatingly, several environmental factors associated with MS pathogenicity were proven to regulate this miRNA expression. Vitamin D deficiency, Epstein-Barr virus (EBV), obesity, alcohol consumption and cigarette smoking were all associated with MS pathogenicity previously and have been associated with miR-155 [19]. Vitamin D, one of the major environmental protective agents against MS, was found to attune $\mathrm{M} \emptyset$ induced inflammation via targeting miR-155 [24]. While EBV, one of the major risk factors for MS, can upregulate this miRNA [25-33]. Obesity, another MS risk factor, is characterized by the over-accumulation of proinflammatory M $\emptyset$ (M1) [34-35]. M1 cells are marked by the increased miR-155-5p and it is thought that this miRNA control M1 polarization [36-37]. In an interesting article, miR-155 were found to be upregulated in the brain by alcohol diet, another MS stimulator $[23,38]$. Alcohol consumption was recorded to provoke neuro-inflammation in mice through miR-155 induction [23]. More so, cigarette smoke-induced inflammation could result from the upregulation of miR-155 [39]. Those points may indicate the importance of this miRNA and the need to be further analyzed regarding environment-induced MS.

This miRNA has been documented to manipulate MS patients' body by several means. When investigating MS, Moore et al have found significant increase of miR-155 in circulating CD14+ monocytes and active lesion (CD68+ cells) comparing to healthy controls cells. They have proven the role of miR-155 as a proinflammatory regulator of macrophages and microglia polarization. Also, in their report, they found that miR-155 transfected in myeloid cells can increase TNF $\alpha, \mathrm{M} 1$-associated surface markers (CD80, CD86, and CCR7) and enhance the allogeneic T-cell responses [40]. Jevtić and his group, subsequently, have indicated the role of miR155 in re-activation of encephalitogenic CD4+ T cells in EAE rats [41]. Interestingly, Lopez-Ramirez and his colleagues claimed miR155 as a negative regulator of BBB function that targets cell-cell complex molecules (annexin-2 and claudin-1) and focal adhesion components (DOCK-1 and syntenin-1). In their report, miR-155 increased expression could mimic cytokine-induced alterations 
in junctional organization and increase the permeability, while inhibition of miR-155 could prevent cytokine-induced increase in the permeability [42]. While, Cerutti et al indicated the role of brain endothelium miR-155 up-regulation in extravagating the adhesion to award monocyte and T cells. This was partially caused by the miR-155 modulation of leukocyte migration include intercellular adhesion molecule-1 (ICAM-1) and vascular cell adhesion molecule-1 (VCAM-1) [42].

In Noorbakhsh et al paper, miR-155 was associated with the suppression of allopregnanolone, an important neurosteroid, in both MS patient and EAE models. Supplementation of this neurosteroid in EAE models was accompanied by decreased neuropathology, including neuroinflammation, myelin and axonal injury and reduced neurobehavioral deficits [43]. Notably, Singh et al identified miR-155 as a biomarker for MS that can increase in expression 6 days before the onset of the EAE disease in urine exosomes, plasma, and spinal cord; emphasizing it is role in early pathogenicity of EAE [44]. In 2011, Paraboschi and his group have identified the genetics factors that associate miR-155 with MS; a haplotype of 3 SNPs mapped in the mir-155 gene (P = 0.035; OR $=1.36,95 \% \mathrm{CI}=1.05-1.77$ ) [9]. Although, Quinn et al signify the role of the transcription factor Ets2 as a key regulator in miR-155 inflammatory response and that Ets2 deficient mice displayed defective immunological responses [45]. Ets2 was unfortunately not analyzed previously for its' relation to MS.

It is worth noting that while Waschbisch et al noted that glatiramer acetate (GA) treatment, the first approved treatment for MS, has no effect on this miRNA, Singh et al noted that miR-155 is one of the GA-responsive biomarkers [8,46-47]. Fortunately, natalizuma, fingolimod and Dimethyl fumarate (DMF) could regulate the miR-155 expression in MS patients $[48,10]$. Interestingly, high-dose ascorbic acid (AA) monotherapy can also modulate miR-155 [49]. One captivating article had discussed the effect of Autologous hematopoietic stem cell transplantation (AHSCT) on regulating miRNA profile; of which miR-155 [50]. In conclusion, miR-155 is one of MS biomarkers that can be detected in patient body fluids before the onset of the disease, contribute to disease pathogenicity and have been documented to increase in expression during relapses stages. This miRNA contributes to inflammation, BBB infiltration, and neuropathology processes. It is thought that MS patient genetics factors can affect the expression of this miRNA. Fortunately, current MS treatments have been documented to modulate the expression of miR-155. MS pathology and the true modulation effect of MS modulators are still questionable, here we explore one side of the story in aim to fully understand the whole picture.

\section{Declarations}

Author Contribution: Eiman M. A. Mohammed alone is responsible for the content and writing of this paper. The author has read and approved the final manuscript.

\section{References}

1. Mohammed EMA (2016) Elucidating the Molecular Basis of Multiple Sclerosis and Understanding the Disease Pathophysiology. Immunome Res 12: 125.
2. Stoicea N, Du A, Lakis DC, Tipton C, Arias-Morales CE et al. (2016) The MiRNA Journey from Theory to Practice as a CNS Biomarker. Front Genet 7: 11 .

3. Fenoglio C, Ridolfi E, Galimberti D, Scarpini E (2012) MicroRNAs as active players in the pathogenesis of multiple sclerosis. Int J Mol Sci 13(10): 13227-13239.

4. Murugaiyan G, da Cunha AP, Ajay AK, Joller N, Garo LP (2015) MicroRNA-21 promotes Th17 differentiation and mediates experimental autoimmune encephalomyelitis. J Clin Invest 125(3): 1069-1080.

5. Raphael I, Webb J, Stuve O, Haskins W, Forsthuber T9 (2015) Body fluid biomarkers in multiple sclerosis: how far we have come and how they could affect the clinic now and in the future. Expert Rev Clin Immunol 11(1): 69-91.

6. Otaegui D, Baranzini SE, Armañanzas R, Calvo B, Muñoz-Culla M et al. (2009) Differential micro RNA expression in PBMC from multiple sclerosis patients. PLoS One 4(7): e6309.

7. Junker A, Krumbholz M, Eisele S, Mohan H, Augstein F, et al. (2009) MicroRNA profiling of multiple sclerosis lesions identifies modulators of the regulatory protein CD47. Brain 132(Pt 12): 3342-3352.

8. Waschbisch A, Atiya M, Linker RA, Potapov S, Schwab S, et al. (2011) Glatiramer acetate treatment normalizes deregulated microRNA expression in relapsing remitting multiple sclerosis. PLoS One 6(9): e24604.

9. Paraboschi EM, Soldà G, Gemmati D, Orioli E, Zeri G (2011) Genetic association and altered gene expression of mir-155 in multiple sclerosis patients. Int J Mol Sci 12(12): 8695-8712.

10. Michell Robinson MA, Moore CS, Healy LM, Osso LA, Zorko N, et al. (2015) Effects of fumarates on circulating and CNS myeloid cells in multiple sclerosis. Ann Clin Transl Neuro 3(1): 27-41.

11. Mycko MP, Cichalewska M, Cwiklinska H, Selmaj KW (2015) miR-155-3p Drives the Development of Autoimmune Demyelination by Regulation of Heat Shock Protein 40. J Neurosci 35(50): 16504-16515.

12. McCoy CE (2017) miR-155 Dysregulation and Therapeutic Intervention in Multiple Sclerosis. Adv Exp Med Biol 1024: 111-131.

13. Niwald M, Migdalska Sęk M, Brzeziańska Lasota E (2017) Evaluation of Selected MicroRNAs Expression in Remission Phase of Multiple Sclerosis and Their Potential Link to Cognition, Depression, and Disability. J Mol Neurosci 63(3-4): 275-282.

14. Gerrard B, Singh V, Babenko O, Gauthier I, Wee Yong V et al. (2017) Chronic mild stress exacerbates severity of experimental autoimmune encephalomyelitis in association with altered non-coding RNA and metabolic biomarkers. Neuroscience 359: 299-307.

15. Dolati S, Aghebati Maleki L, Ahmadi M, Marofi F, Babaloo Z et al. (2018) Nanocurcumin restores aberrant miRNA expression profile in multiple sclerosis, randomized, double-blind, placebo-controlled trial. J Cell Physiol 233(7): 5222-5230.

16. Tarassishin L, Loudig O, Bauman A, Shafit Zagardo B (2011) Interferon regulatory factor 3 inhibits astrocyte inflammatory gene expression through suppression of the proinflammatory miR-155 and miR-155. Glia 59(12): 1911-1922.

17. Chen Y, Liu W, Sun T, Huang Y, Wang Y, et al. (2013) 1,25-Dihydroxyvitamin D promotes negative feedback regulation of TLR signaling via targeting microRNA-155-SOCS1 in macrophages. J Immunol 190(7): 3687-3695.

18. Zhang J, Cheng Y, Cui W, Li M, Li B, et al. (2014) MicroRNA-155 modulates Th1 and Th17 cell differentiation and is associated with multiple sclerosis and experimental autoimmune encephalomyelitis. J Neuroimmunol 266(1-2): 56-63.

19. Mohammed EMA (2016) Multiple sclerosis is prominent in the Gulf states: Review Pathogenesis. 3(2): 19-38.

20. Garo LP, Murugaiyan G (2016) Contribution of MicroRNAs to autoimmune diseases. Cell Mol Life Sci 73(10): 2041-2051. 
21. Junker A, Hohlfeld R, Meinl E (2011) The emerging role of microRNAs in multiple sclerosis. Nat Rev Neurol 7(1): 56-59.

22. Aslani S, Jafari N, Javan MR, Karami J, Ahmadi M, et al. (2017) Epigenetic Modifications and Therapy in Multiple Sclerosis. Neuromolecular Med Mar 19(1): 11-23.

23. Lippai D, Bala S, Csak T, Kurt Jones EA, Szabo G, et al. (2013) Chronic Alcohol-Induced microRNA-155 Contributes to Neuroinflammation in a TLR4-Dependent Manner in Mice. PLoS ONE 8(8): e70945.

24. Chen Y, Liu W, Sun T, Huang Y, Wang Y, et al. (2013) 1,25-Dihydroxyvitamin D promotes negative feedback regulation of TLR signaling via targeting microRNA-155-SOCS1 in macrophages. J Immunol 190(7): 3687-3695.

25. Godshalk SE, Bhaduri McIntosh S, Slack FJ (2008) Epstein-Barr virusmediated dysregulation of human microRNA expression. Cell Cycle 7(22): 3595-3600.

26. Rosato P, Anastasiadou E, Garg N, Lenze D, Boccellato F, et al. (2012) Differential regulation of miR-21 and miR-146a by Epstein-Barr virusencoded EBNA2. Leukemia 26(11): 2343-2352.

27. Yang GD, Huang TJ, Peng LX, Yang CF, Liu RY, et al. (2013) EpsteinBarr Virus Encoded LMP1 upregulates microRNA-21 to promote the resistance of nasopharyngeal carcinoma cells to cisplatin-induced Apoptosis by suppressing PDCD4 and Fas-L. PLoS One 8(10): e78355.

28. Yang F, Liu Q, Hu CM (2015) Epstein-Barr virus-encoded LMP1 increases miR-155 expression, which promotes radio resistance of nasopharyngeal carcinoma via suppressing UBQLN1. Eur Rev Med Pharmacol Sci 19(23): $4507-4515$

29. Gatto G, Rossi A, Rossi D, Kroening S, Bonatti S, et al. (2008) Epstein-Barr virus latent membrane protein 1 trans-activates miR-155 transcription through the NF-kappaB pathway. Nucleic Acids Res 36(20): 6608-6619.

30. Yin Q, McBride J, Fewell C, Lacey M (2008) MicroRNA-155 is an EpsteinBarr virus-induced gene that modulates Epstein-Barr virus-regulated gene expression pathways. J Virol 82(11): 5295-5306.

31. Du ZM, Hu LF, Wang HY, Yan LX, Zeng YX (2011) Upregulation of MiR-155 in nasopharyngeal carcinoma is partly driven by LMP1 and LMP2A and downregulates a negative prognostic marker JMJD1A. PLoS One 6(4): e19137.

32. Zuo L, Yue W, Du S, Xin S, Zhang J, et al. (2017) An update: Epstein-Barr virus and immune evasion via microRNA regulation. Virol Sin 32(3): 175-187.

33. Albanese M, Tagawa T, Buschle A, Hammer Schmidt W (2017) MicroRNAs of Epstein-Barr Virus Control Innate and Adaptive Antiviral Immunity. J Virol 91(16): pii: e01667-16.

34. Karkeni E, Astier J, Tourniaire F, El Abed M et al. (2016) Obesityassociated Inflammation Induces microRNA-155 Expression in Adipocytesand Adipose Tissue: Outcome on Adipocyte Function. J Clin Endocrinol Metab 101(4): 1615-1626.

35. Kamanemi S, Ying W, Bazer FW, Zhou B (2013) MicroRNA Regulated Macrophage Activation in Obesity. J Nutr Food Sci 3: 217.

36. Zhang Y, Zhang M, Zhong M, Suo Q Lv K, et al. (2013) Expression profiles of miRNAs in polarized macrophages. Int J Mol Med 31(4): 797-802.
37. Essandoh K, Li Y, Huo J, Fan GC (2016) MiRNA-Mediated Macrophage Polarization and its Potential Role in the Regulation of Inflammatory Response. Shock 46(2): 122-131.

38. Natarajan SK, Pachunka JM, Mott JL (2015) Role of microRNAs in Alcohol-Induced Multi-Organ Injury. Biomolecules 5(4): 3309-3338.

39. Conickx G, Avila Cobos F, van den Berge M, Faiz A, Timens W, et al. (2017) microRNA profiling in lung tissue and bronchoalveolar lavage of cigarette smoke-exposed mice and in COPD patients: a translational approach. Sci Rep 7(1): 12871.

40. Moore CS, Rao VT, Durafourt BA, Bedell BJ, Ludwin SK, et al. (2013) miR-155 as a multiple sclerosis-relevant regulator of myeloid cell polarization. Ann Neurol 74(5): 709-720.

41. Jevtić B, Timotijević G, Stanisavljević S, Momčilović M, Mostarica Stojković M, et al. (2015) Micro RNA-155 participates in re-activation of encephalitogenic T cells. Biomed Pharmacother 74: 206-210.

42. Cerutti C, Soblechero-Martin P, Wu D, Lopez-Ramirez MA, de Vries $\mathrm{H}$, et al. (2016) MicroRNA-155 contributes to shear-resistant leukocyte adhesion to human brain endothelium in vitro. Fluids Barriers CNS 13(1): 8.

43. Noorbakhsh F, Ellestad KK, Maingat F, Warren KG, Han MH, et al. (2011) Impaired neurosteroid synthesis in multiple sclerosis. Brain 134(Pt 9): 2703-2721.

44. Singh J, Deshpande M, Suhail H, Rattan R (2016) Targeted Stage-Specific Inflammatory microRNA Profiling in Urine During Disease Progression in Experimental Autoimmune Encephalomyelitis: Markers of Disease Progression and Drug Response. J Neuroimmune Pharmacol 11(1): 8497.

45. Quinn SR, Mangan NE, Caffrey BE, Gantier MP, Williams BR, et al. (2014) The role of Ets2 transcription factor in the induction of microRNA-155 (miR-155) by lipopolysaccharide and its targeting by interleukin-10. J Biol Chem 289(7): 4316-4325.

46. Racke MK, Lovett-Racke AE (2011) Glatiramer acetate treatment of multiple sclerosis: an immunological perspective. J Immunol 186(4): 1887-1890.

47. La Mantia L, Munari LM, Lovati R (2010) Glatiramer acetate for multiple sclerosis. Cochrane Database Syst Rev 12(5): CD004678.

48. Mameli G,Arru G, CaggiuE, Niegowska M,Leoni S, etal.(2016) Natalizumab Therapy Modulates miR-155, miR-26a and Proinflammatory Cytokine Expression in MS Patients. PLoS One11(6): e0157153.

49. Moens B, Decanine D, Menezes SM, Khouri R, Silva-Santos G (2012) Ascorbic acid has superior ex vivo antiproliferative, cell death-inducing and immunomodulatory effects over IFN- $\alpha$ in HTLV-1-associated myelopathy. PLoS Negl Trop Dis 6(7): e1729.

50. Arruda LC, Lorenzi JC, Sousa AP, Zanette DL, Palma PV, et al. (2015) Autologous hematopoietic SCT normalizes miR-16, -155 and -142-3p expression in multiple sclerosis patients. Bone Marrow Transplant Mar 50(3): 380-389. 


\section{ISSN: 2574-1241}

DOI: 10.26717/BJSTR.2018.09.001841

Eiman MA Mohammed. Biomed J Sci \& Tech Res

(C) This work is licensed under Creative

Submission Link: https://biomedres.us/submit-manuscript.php

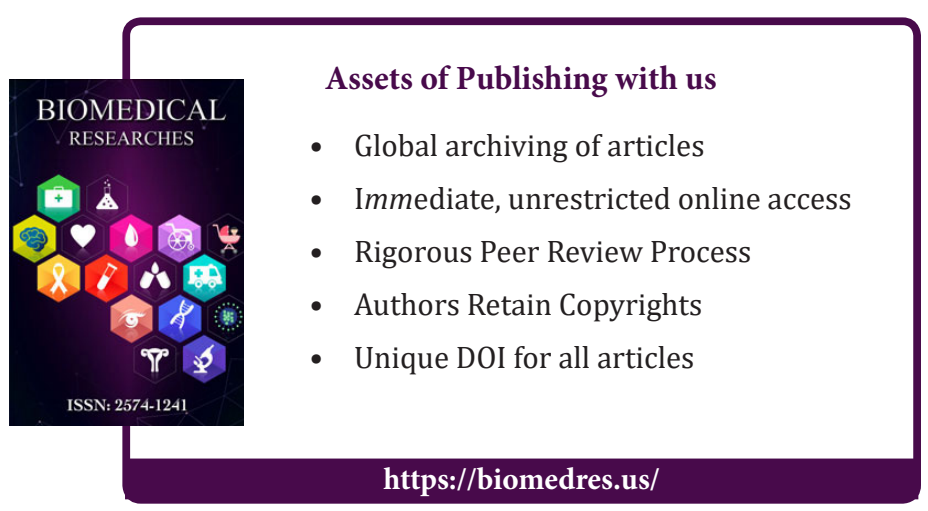

